\title{
COVID-19 and rheumatology: first steps towards a different future?
}

\author{
lain B Mclnnes
}

As a rheumatology community, we looked on the new decade with excitement and ambition yet now instead find ourselves amidst the most significant global public healthcare challenge in our lifetimes. ${ }^{1}$ The pandemic arising from severe acute respiratory syndrome coronavirus- 2 has rapidly changed our personal and professional outlook. The rheumatology community has risen promptly to this challenge and is already demonstrating remarkable partnership in its global and integrated approach. Rheumatology is a discipline that has advanced with remarkable pace in the last decades, driven by revolutionary strategic approaches to the management of rheumatic and musculoskeletal diseases (RMDs), together with increasingly effective application of the wealth of possibilities contained in modern molecular medicine. New therapeutics abound based on ever clearer understanding of the pathogenesis of our diseases and the extraordinary capacity in the biotech and pharmaceutical industry sector to capitalise on the same for therapeutic benefit. These are precisely the skills and approaches that are now essential as we combat Covid-19. The immediate public health measures that are currently in force, however effective, will eventually require a robust underpinning molecular medical response in the form of vaccines and new therapeutics to achieve the long-term goal of normalising quality of life for the majority. Rheumatology may therefore be ideally placed to support our infectious diseases and critical care colleagues as we enter poorly charted clinical territory. This month in the Annals of Rheumatic Diseases (ARD), we read the first products of the widespread activities concerning RMDs emerging as we move to combat the virus and its various clinical manifestations.

Poorer outcomes to Covid-19 seem to particularly occur in older patients and those with comorbidities, for example, chronic obstuctive pulmonary disease (COPD), coronary heart disease (CHD),

Correspondence to Professor lain B McInnes, Institute of Infection, Immunity and Inflammation, University of Glasgow, Glasgow G12 8QQ, UK; iain.mcinnes@glasgow.ac.uk hypertension and diabetes. ${ }^{1}$ Immune suppression is similarly flagged as a risk factor. A key question for our community therefore is the extent to which risk of infection a priori, or progression thereafter, are altered for people with RMDs taking immune modifiers, for example, glucocorticoids, biologicals, targeted synthetic disease-modifying antirheumatic drugs (DMARDs), or indeed conventional DMARDs. In the $A R D$, Monti and colleagues ${ }^{2}$ provide a clinical description of Covid-19 in patients with inflammatory arthritis receiving immune suppressive therapies. A reassuring outcome is reported in this small sample; moreover, on infection, all patients discontinued their immune modifiers without flaring despite intercurrent viral stimulus. The authors also helpfully point to prior experiences following Middle East respiratory syndrome and severe acute respiratory syndrome outbreaks in which immune suppression, transplantation and cancer did not notably confer poorer outcomes. At present, therefore, most recommendations suggest continuation of immune modifiers in general unless Covid-19 is confirmed. This highly commendable report, generated in challenging circumstances, does not, however, definitively address the incidence and implication of Covid-19 in RMDs. To this end, the EULAR-COVID-19 Database has been launched, comprising a European paediatric and adult database designed to monitor and report on outcomes of Covid-19 occurring in patients with RMDs. In turn, it is designed to work alongside the Covid-19 Global Rheumatology Alliance that comprises rheumatologists and epidemiologists and has now formed a global repository for Covid-19 cases with RMDs. These initiatives will provide short-term clinical advisory information and will serve the purpose of longterm vigilance across the age groups as we anticipate the psychological impacts, immune deregulatory potential and also perhaps even altered comorbidities that may ensue post-Covid-19 in people with underlying RMDs.

A second topical and rapidly evolving discussion concerns the role or otherwise of immune stimulation and host responses in the evolution of Covid-19. Antiviral agents are urgently required to address patients with Covid-19, but existing agents as yet appear not consistently effective. ${ }^{3-5}$ Remdesivir may offer more benefit though this is being trialled currently. In this context, focus is falling on immune modulation to limit tissue damage and especially progression to multiorgan failure. It is apparent that Covid-19 has a phasic component ${ }^{3}$ with a majority exhibiting relatively mild symptomatology with no known sequelae. A smaller but clinically significant subgroup shows progression to a more critical illness. A further subgroup apparently develops a syndrome with features of a 'cytokine storm', reminiscent of, but identical to, haemophagocytic lymphohistiocytosis or that seen following chimeric antigen receptor $\mathrm{T}$ (CAR-T) cell therapeutics. ${ }^{6}$ Notably, we should not assume that this is a sequence of events in a given individual as outcome could reflect quite discrete host characteristics; eventually, these states may be identifiable on the basis of molecular stratification. Interest has fallen accordingly on the use of currently available immune modifiers. Early enthusiasm for hydroxychloroquine (HCQ), ${ }^{7}$ which has theoretical effects on virus cell biology via alteration of $\mathrm{pH}$ in endosomes, lysosomes and Golgi apparatus, together with capacity to block viral replication ex vivo, has been tempered by the lack of high-quality randomised controlled trial data to support its use in clinic, this despite its approval in some regions. In $A R D$, Spinelli and colleagues ${ }^{8}$ offer an insightful review of this issue and remark on the potential for prophylactic use. Others have also commented on the widespread use of HCQ in the absence of controlled evidence, ${ }^{9} 10$ noting also that it is not without side effects, especially in the context of potential virus-induced cardiac damage (and prolonged QT interval). The data shall decide as formal trials are ongoing but at present there should perhaps be some restraint in its widespread application. Meantime there is a further direct implication of this high uptake of HCQ use, namely a shortage of drug supply with grave consequences for that group of people with RMDs dependent on it for their maintained wellbeing. As such, there is an urgent need for increased manufacture and protected supply of HCQ to meet the needs of the RMD population.

The immune stimulation apparent in some patients has led many to consider or apply the use of cytokine inhibiting agents, especially tocilizumab and sarilumab, that 
inhibit interleukin-6 receptor (IL-6R) and have found utility in hemophagocytic lymphohistiocytosis (HLH) and CAR-T cell cytokine storm syndrome. An increasing range of immune modifiers are now being considered for intervention including interleukin-6 receptor inhibitor (IL-6Ri), interleukin-6 inhibitor (IL-6i), granulocyte-macrophage colonystimulating factor (GM-CSFi), Janus Kinase inhibitor (JAKi), tumour necrosis factor inhibitor (TNFi) and others. These agents are not without a significant adverse event profile, and understandable unease is developing in the critical care community as to their unregulated application, although use is compassionate and often in extremis. Rheumatologists are expert in the use of these agents; we should be to the fore in advising around their application noting risks and benefits are not yet clear and should not be taken for granted in Covid-19. It is preferable, but not always achievable, that these agents are explored in the context of clinical trials though the compassionate use and observational cohorts already published offer useful insights.

Finally, what are we now to do in terms of treatment recommendations in the era of Covid-19? Ideally learned bodies, including European League Against Rheumatism (EULAR), American College of Rheumatology (ACR) and Asia Pacific League Against Rheumatism (APLAR), will offer consistent advice with sufficient regional flavour as to allow pragmatic application. Despite the pandemic, we should try to adhere as far as possible to agreed methodologies and rigour. That said, all current approaches are hampered by a lack of data-those will however emerge rapidly from initiatives such as those described above and behove our community to respond quickly and efficiently to place the evidence base behind our recommendations, that in turn must be dynamic and agile to offer the best outcomes for our patients. These are challenging times indeed but also rich with opportunity for a rheumatology community response that is creative, collegiate and compassionate.

\section{Handling editor Josef S Smolen}

Funding The authors have not declared a specific grant for this research from any funding agency in the public, commercial or not-for-profit sectors.

\section{Competing interests None declared.}

Patient and public involvement Patients and/or the public were not involved in the design, or conduct, or reporting, or dissemination plans of this research.

\section{Patient consent for publication Not required.}

Provenance and peer review Commissioned; internally peer reviewed.

This article is made freely available for use in accordance with BMJ's website terms and conditions for the duration of the covid-19 pandemic or until otherwise determined by BMJ. You may use, download and print the article for any lawful, non-commercial purpose (including text and data mining) provided that all copyright notices and trade marks are retained.

(C) Author(s) (or their employer(s)) 2020. No commercial re-use. See rights and permissions. Published by BMJ.

Check for updates

To cite Mclnnes IB. Ann Rheum Dis 2020;79:551-552.

Received 3 April 2020

Revised 3 April 2020

Accepted 3 April 2020
Published Online First 24 May 2020

Ann Rheum Dis 2020;79:551-552.

doi:10.1136/annrheumdis-2020-217494

\section{REFERENCES}

1 Zhou F, Yu T, Du R, et al. Clinical course and risk factors for mortality of adult inpatients with COVID-19 in Wuhan, China: a retrospective cohort study. Lancet 2020;395:1054-62.

2 Monti S, Balduzzi S, Delvino P, et al. Clinical course of COVID-19 in a series of patients with chronic arthritis treated with immunosuppressive targeted therapies. Ann Rheum Dis 2020;79:667-8.

3 Chen G, Wu D, Guo W, et al. Clinical and immunologic features in severe and moderate coronavirus disease 2019. J Clin Invest 2020;137244:1-3

4 Wu J, Li W, Shi X, et al. Early antiviral treatment contributes to alleviate the severity and improve the prognosis of patients with novel coronavirus disease (COVID-19). J Intern Med 2020. doi:10.1111/ joim. 13063. [Epub ahead of print: 27 Mar 2020].

5 Cao B, Wang Y, Wen D, et al. A trial of LopinavirRitonavir in adults hospitalized with severe Covid-19. N Engl J Med 2020. doi:10.1056/NEJMoa2001282. [Epub ahead of print: 18 Mar 2020].

6 Mehta P, McAuley DF, Brown M, et al. Hlh across speciality collaboration, UK. COVID-19: consider cytokine storm syndromes and immunosuppression. Lancet 2020;395:1033-4.

7 Gautret P, Lagier J-C, Parola P, et al. Hydroxychloroquine and azithromycin as a treatment of COVID-19: results of an open-label non-randomized clinical trial. Int J Antimicrob Agents 2020;20:105949.

8 Spinelli FR, Ceccarelli F, Di Franco M, et al. To consider or not antimalarials as a prophylactic intervention in the SARS-CoV-2 (Covid-19) pandemic. Ann Rheum Dis 2020;79:666-7.

9 AHJ K, Sparks JA, Liew JW, et al. COVID-19 Global Rheumatology Alliance. A Rush to Judgment? Rapid Reporting and Dissemination of Results and Its Consequences Regarding the Use of Hydroxychloroquine for COVID-19. Ann Intern Med 2020.

10 Guastalegname M, Vallone A. Could chloroquine / hydroxychloroquine be harmful in coronavirus disease 2019 (COVID-19) treatment? Clin Infect Dis 2020:pii: ciaa321. 